\title{
Effect of ovarian endometrioma on uterine and ovarian blood flow in infertile women
}

\author{
This article was published in the following Dove Press journal: \\ International Journal of Women's Health \\ 28 November 2016 \\ Number of times this article has been viewed
}

\author{
Akmal El-Mazny \\ Ahmed Kamel \\ Wafaa Ramadan \\ Sherine Gad-Allah \\ Suzy Abdelaziz \\ Ahmed M Hussein \\ Department of Obstetrics and \\ Gynecology, Faculty of Medicine, \\ Cairo University, Cairo, Egypt
}

Background: Angiogenesis has been found to be among the most important factors in the pathogenesis of endometriosis. The formation of new blood vessels is critical for the survival of newly implanted endometriotic foci. The use of 3-D power Doppler allows for the demonstration of the dynamic vascular changes that occur during the process of in vitro fertilization (IVF). We aimed to evaluate the effect of ovarian endometrioma on uterine and ovarian blood flow in infertile women.

Materials and methods: In a case-control study at a university teaching hospital, 138 women with unilateral ovarian endometrioma scheduled for IVF were compared to 138 women with male-factor or unexplained infertility. In the mid-luteal (peri-implantation) phase of the cycle, endometrial thickness, uterine and ovarian artery pulsatility index and resistance index, endometrial and ovarian volume, 3-D power Doppler vascularization index (VI), flow index (FI), and vascularization FI (VFI) values were measured in both groups.

Results: There were no significant differences $(P>0.05)$ in endometrial thickness, uterine ovarian artery pulsatility index and resistance index, endometrial and ovarian volume, or VI, FI, and VFI between the two groups. Furthermore, the endometrial and ovarian Doppler indices were not influenced by endometrioma size. No significant differences were observed in the ovarian Doppler indices between endometrioma-containing ovaries and contralateral ovaries.

Conclusion: Ovarian endometrioma is not associated with impaired endometrial and ovarian blood flows in infertile women scheduled for IVF, and it is not likely to affect endometrial receptivity or ovarian function through a vascular mechanism.

Keywords: 3-D power Doppler, endometrioma, IVF, uterine and ovarian blood flow

\section{Introduction}

The core definition of endometriosis is when endometrial glands and stoma are identified outside the uterine cavity. The true incidence of endometriosis is difficult to calculate; however, it is estimated to affect $2 \%-10 \%$ of women in their reproductive age, and $50 \%$ of patients complain of infertility. ${ }^{1}$

The success rate of in vitro fertilization (IVF)/intracytoplasmic sperm injection has been reported to be affected by the presence or absence of endometriosis. Pregnancy rates after IVF/intracytoplasmic sperm injection were decreased in patients with stage III and IV endometriosis when compared to those with tubal factor infertility. ${ }^{2}$

Angiogenesis has been found to be among the most important factors in the patho-

Correspondence: Ahmed Kame

Department of Obstetrics and

Gynecology, Faculty of Medicine, Cairo

University, Cairo I I43I, Egypt

Tel +20 I| 20022332

Fax +20 223643554

Email dr.ahmed.m.kamel@gmail.com genesis of endometriosis. Increased levels of angiogenic factors have been identified in the peritoneal fluid of patients with endometriomas. ${ }^{3}$ The formation of new blood vessels is critical for the survival of newly implanted endometriotic foci, and they are recruited by endometriotic lesions through angiogenesis. ${ }^{4}$ 
Ultrasonographic examination is the most commonly used modality for the assessment of patients with suspected endometriosis, and its efficiency in the detection of ovarian endometriomas is well established. ${ }^{4}$ The use of 3-D power Doppler as a prognostic tool for IVF outcome in patients with endometriomas has been previously described, as it allows for the demonstration of the dynamic vascular changes that occur during the process of IVF. ${ }^{5}$ The aim of this study was to evaluate the effect of ovarian endometrioma on uterine and ovarian blood flow in infertile women scheduled for IVF.

\section{Materials and methods}

In a case-control study, women with unilateral ovarian endometrioma scheduled for IVF were recruited in our target group over the course of 4 years. Transvaginal ultrasonography (TVUS) was used for the diagnosis of ovarian endometrioma. The mainstay of diagnosis was based on visualizing rounded homogeneous hypoechoic tissue with low-level echoes within the ovary (Figure 1), as described by Moore et al. ${ }^{6}$ A matched control group with a similar number consisted of women with either unexplained or male-factor infertility scheduled for IVF.

A study protocol was submitted and approved by the Scientific Research Committee of the Obstetrics and Gynecology Department of Cairo University on February 16, 2012, and all participants signed an informed consent form. Recruitment was done at the Fertility Clinic of Kasr Alaniy Assisted Conception Unit, and the setting of this study was the Ultrasound Unit of the Obstetrics and Gynecology Department at Kasr Alainy Hospital, Cairo University. Recruitment lasted from March 2012 to June 2016.

Inclusion criteria were age-group 25-35 years, body mass index (BMI) $<30 \mathrm{~kg} / \mathrm{m}^{2}$, normal basal hormonal profile, either

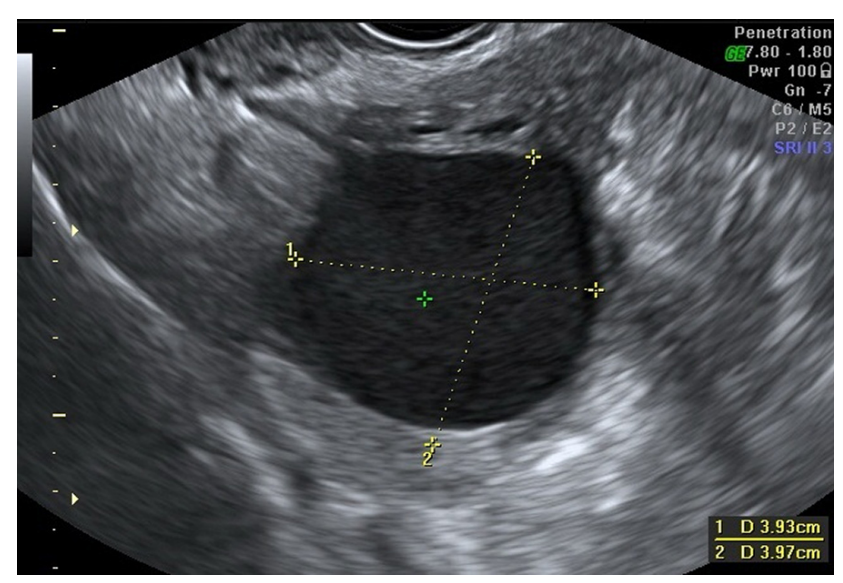

Figure I Transvaginal ultrasonography of the endometrioma. primary or secondary infertility with a duration of more than 2 years, regular menstrual cycle, ovulation documented by TVUS and/or normal mid-luteal serum progesterone levels, and a normal uterine cavity screened by hysterosalpingography, TVUS, and/or hysteroscopy.

Women were excluded from our study if they were smokers, lactating, had had previous pelvic surgery, including cesarean section, or if they had any pelvic pathology, including uterine fibroids, ovarian cysts (other than endometrioma), and hydrosalpinx. Women were also excluded if they had a general disease or were on any medication that could affect pelvic blood flow.

All ultrasound examinations were done by a single highly trained operator on days 20-22 (mid-luteal phase), which coincided with the peri-implantation window of the cycle. We used a Voluson 730 ultrasound machine (GE, Boston, MA, USA). We took the maximum thickness of the endometrium in the sagittal plane on both sides of the midline (double layer) as our measurement for endometrial thickness.

We needed to assess blood flow in the uterine and ovarian arteries. Color Doppler in the 2-D mode was used to obtain flow-velocity waveforms from the ascending main branch of the uterine artery, and the vessel was identified at the level of the internal os. The same technique was employed to search for the ovarian artery at the ovarian hilum, and was identified by being the largest vessel there. Pulsatility index (PI) and resistance index (RI) values of both the right and left uterine and ovarian arteries were obtained, and then the averaged measurements of the uterine and ovarian PI and RI were calculated and recorded.

The ultrasound settings for this study were standardized according to El-Mazny et al, ${ }^{7}$ where we switched the ultrasound machine to the 3-D mode with power Doppler. The frequency was set at 3-9 MHz, pulse-repetition frequency at $0.6 \mathrm{kHz}$, gain at -4 , and wall-motion filter at low 1 . The built-in VOCAL (virtual organ computer-aided analysis) imaging program was used to measure and record the endometrial volume and blood-flow indices, as seen in (Figure 2). The same technique was utilized to measure ovarian volume (excluding endometrioma) and blood flow, as seen in (Figure 3). The averaged ovarian volume and 3-D power Doppler indices were also recorded.

The parameters measured were the vascularization index (VI), which measures the ratio of the number of color voxels to the total number of voxels (\%) and also represents vascularity (the presence of blood vessels), the flow index (FI), which measures the mean power Doppler-signal intensity 


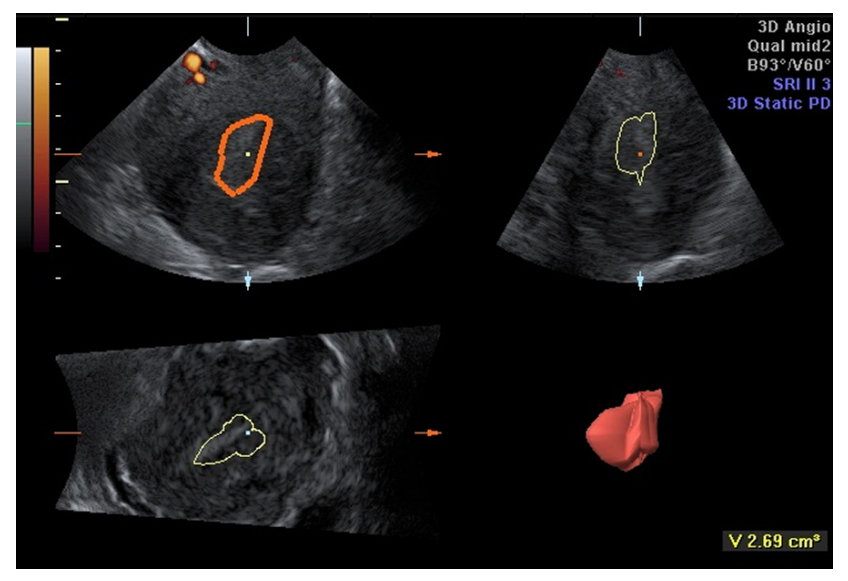

Figure 2 Virtual organ computer-aided analysis of the endometrium.

$(0-100)$ and constitutes the average intensity of blood flow, and the vascularization FI (VFI), which is calculated by multiplying VI and FI (0-100) and represents a combination of vascularity and flow intensity. ${ }^{7}$

Intraobserver variability of the ultrasound operator was determined using the intraclass correlation coefficient (ICC), where the operator repeated the measurements for the VI, FI, and VFI twice in 15 cases of the endometrioma group and 20 cases in the nonendometrioma group. The mean ICC was calculated and recorded according to Järvelä et $\mathrm{al}^{8}$ for VI, FI, and VFI: 0.921 (95\% confidence interval [CI] 0.899-0.943), 0.896 (95\% CI 0.832-0.96), and 0.955 (95\% CI 0.921-0.989), respectively, in the endometrioma group. ICCs for the nonendometrioma group were 0.935 (95\% CI $0.887-0.983$ ), 0.912 (95\% CI $0.885-0.939$ ), and 0.929 (95\% CI 0.891-0.968) for the VI, FI, and VFI, respectively.

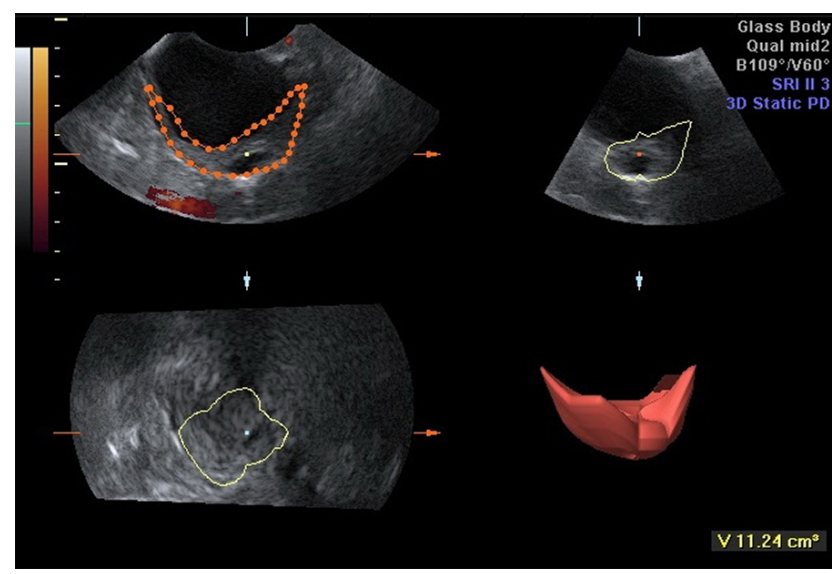

Figure 3 Virtual organ computer-aided analysis of the ovary (excluding endometrioma).

\section{Statistical analysis}

Continuous data are expressed as mean \pm standard deviation $(95 \%$ CI). Data were compared using Student's $t$-test or Mann-Whitney $U$-test as appropriate. Categorical data were expressed as number (\%), and comparison was done using Fisher's exact test. ICCs were used to assess intraobserver reliability using one-way random mean measures. A twotailed $P$-value $<0.05$ was considered statistically significant. Statistical analysis of the data was performed using the SPSS version 20.0 (IBM, Armonk, NY, USA).

\section{Results}

Over 4 years, we recruited 138 infertile women with unilateral ovarian endometrioma scheduled for IVF in the study group. Endometrioma was encountered in the right ovary in $79(57.2 \%)$ women and in the left ovary in $59(42.8 \%)$. The mean diameter of the endometrioma was $35.73 \pm 7.51$ (range 25-65) $\mathrm{mm}$. We enrolled a similar number in the control group, which consisted of 138 women with malefactor $(\mathrm{n}=86,62.3 \%)$ or unexplained $(\mathrm{n}=52,37.7 \%)$ infertility also scheduled for IVF. There were no significant differences in age $(P=0.106)$, parity $(P=0.217)$, type of infertility $(P=0.814)$, duration of infertility $(P=0.429)$, duration of menstrual cycle $(P=0.328)$, or BMI $(P=0.198)$ between the two groups (Table 1$)$.

We compared the endometrial and ovarian Doppler indices between women with and without endometrioma (Table 2). There were no significant differences in endometrial thickness $(P=0.616)$, uterine artery $\mathrm{PI}(P=0.461)$ and RI $(P=0.355)$, ovarian artery PI $(P=0.828)$ and RI $(P=0.844)$, endometrial volume $(P=0.44)$, VI $(P=0.413)$, FI $(P=0.669)$, and VFI $(P=0.810)$, or ovarian volume $(P=0.812)$, VI $(P=0.293)$, FI $(P=0.390)$, and VFI $(P=0.297)$ between the two groups.

We then examined whether the endometrial and ovarian Doppler indices were influenced by endometrioma size (Table 3). There were no significant differences in endometrial thickness $(P=0.402)$; uterine artery PI $(P=0.162)$ and RI $(P=0.264)$; ovarian artery PI $(P=0.467)$ and RI ( $P=0.762)$; endometrial volume $(P=0.514), \mathrm{VI}(P=0.195), \mathrm{FI}$ ( $P=0.115)$, and VFI $(P=0.951)$; or ovarian volume $(P=0.902)$, VI $(P=0.744)$, FI $(P=0.122)$, and VFI $(P=0.432)$ between endometriomas $<40 \mathrm{~mm}(\mathrm{n}=76,55.1 \%)$ and $\geq 40 \mathrm{~mm}$ $(\mathrm{n}=62,44.9 \%)$.

We then compared the ovarian Doppler indices between endometrioma-containing ovaries and contralateral ovaries (Table 4). No significant differences were observed in ovarian artery PI $(P=0.103)$ and RI $(P=0.870)$ or ovarian volume 
Table I Comparison of clinical characteristics between women with and without endometrioma

\begin{tabular}{|c|c|c|c|}
\hline Variable & Endometrioma group* & Control group* & P-value \\
\hline Patients (n) & 138 & 138 & \\
\hline Age (years) & $29.1 \mathrm{I} \pm 3.42(28.02-30.2 \mathrm{I})$ & $30.54 \pm 4.35(29.15-31.93)$ & 0.106 \\
\hline Parity (n) & $0.9 I \pm 0.74$ (0.67-I.I4) & I. I2士0.77 (0.87-I.37) & 0.217 \\
\hline Primary infertility $(n)$ & 93 (67.4\%) & $86(62.3 \%)$ & 0.814 \\
\hline Duration of infertility (years) & $4.98 \pm 2.67(4.12-5.83)$ & $4.5 I \pm 2.62(3.67-5.34)$ & 0.429 \\
\hline Menstrual cycle (days) & $28.24 \pm 1.37(27.8-28.68)$ & $28.57 \pm 1.62(28.06-29.09)$ & 0.328 \\
\hline BMI $\left(\mathrm{kg} / \mathrm{m}^{2}\right)$ & $26.02 \pm 2.63(25.18-26.86)$ & $25.12 \pm 3.51(24-26.24)$ & 0.198 \\
\hline
\end{tabular}

Note: *Values given as mean \pm standard deviation ( $95 \%$ confidence interval) or $\mathrm{n}(\%)$.

Abbreviation: BMI, body mass index.

$(P=0.357)$, VI $(P=0.374)$, FI $(P=0.252)$, and VFI $(P=0.369)$

between the two groups.

\section{Discussion}

The incorporation of 3-D ultrasound and power Doppler into the field of obstetrics, gynecology, and assisted reproduction has been described. ${ }^{9,10}$ The use of VOCAL software for 3-D volume measurement has become faster and more convenient than older methods. The measurement of ovarian volume and stromal blood flow can now be more objectively assessed. ${ }^{11,12}$

This is the first study to evaluate the effect of endometrioma on uterine and ovarian hemodynamics using 3-D power Doppler. Other authors ${ }^{3,4}$ have focused on using 3-D power Doppler to investigate the relationship between pelvic pain and blood flow in cases with ovarian endometrioma. $\mathrm{Wu}$ et $\mathrm{al}^{5}$ reviewed the use of $3-\mathrm{D}$ power Doppler in measuring the effect of cystectomy for endometrioma on ovarian blood flow and correlation with ovarian reserve.
Our results showed that there were no significant differences $(P>0.05)$ in endometrial thickness, uterine and ovarian artery PI and RI, or endometrial and ovarian volume, VI, FI, and VFI between the endometrioma group and the control group. The endometrial and ovarian Doppler indices were not influenced by endometrioma size either. No significant differences were observed in the ovarian Doppler indices between endometrioma-containing ovaries and contralateral ovaries.

In agreement with our findings, Alcázar et $\mathrm{al}^{13}$ reported that color velocity imaging and pulsed Doppler showed no significant difference in ovarian endometriomas and other nonendometriotic masses. Likewise, Huang et $\mathrm{al}^{14}$ found no significant difference in VI, FI, or VFI between ovaries with endometriomas and other benign homogeneous hypoechogenic adnexal cysts. This goes to prove that endometriomas, like other benign cysts, do not alter ovarian stromal blood flow.

On the other hand, in a retrospective study, $\mathrm{Wu}$ et $\mathrm{al}^{12}$ reported significantly decreased ovarian VI, FI, and VFI

Table 2 Comparison of endometrial and ovarian Doppler indices between women with and without endometrioma

\begin{tabular}{|c|c|c|c|}
\hline Variable & Endometrioma group* & Control group* & $P$-value \\
\hline Patients (n) & 138 & 138 & \\
\hline Endometrial thickness (mm) & $10.64 \pm 3.48(9.52-11.75)$ & $11.02 \pm 3.27(9.97-12.07)$ & 0.616 \\
\hline Uterine artery PI & $1.50 \pm 0.27(\mid .4 I-1.58)$ & $1.45 \pm 0.33(1.35-1.56)$ & 0.461 \\
\hline Uterine artery RI & $0.8 \mathrm{I} \pm 0.1 \mathrm{I}(0.77-0.84)$ & $0.79 \pm 0.08(0.76-0.8 I)$ & 0.355 \\
\hline Ovarian artery $\mathrm{PI}$ & $1.58 \pm 0.42(\mid .44-1.71)$ & $1.6 \pm 0.4(1.47-1.72)$ & 0.828 \\
\hline Ovarian artery RI & $0.86 \pm 0.3(0.77-0.96)$ & $0.85 \pm 0.11(0.8 I-0.89)$ & 0.844 \\
\hline Endometrial volume $\left(\mathrm{cm}^{3}\right)$ & $3.47 \pm 1.42(3.0 \mathrm{I}-3.92)$ & $3.79 \pm 2.19(3.09-4.49)$ & 0.44 \\
\hline Endometrial VI (\%) & $0.45 \pm 0.24(0.38-0.53)$ & $0.5 \pm 0.3(0.4-0.59)$ & 0.413 \\
\hline Endometrial FI $(0-100)$ & $28.14 \pm 9.38(25.14-31.14)$ & $28.95 \pm 7.4(26.58-31.31)$ & 0.669 \\
\hline Endometrial VFI $(0-100)$ & $0.33 \pm 0.47(0.18-0.48)$ & $0.35 \pm 0.23(0.27-0.42)$ & 0.81 \\
\hline Ovarian volume $\left(\mathrm{cm}^{3}\right)$ & $9.27 \pm 3.26(8.22-10.31)^{\ddagger}$ & $9.04 \pm 5.16(7.39-10.69)$ & 0.812 \\
\hline Ovarian VI (\%) & $1.74 \pm 0.85(1.47-2.01)^{\ddagger}$ & $2.02 \pm 1.44(1.56-2.48)$ & 0.293 \\
\hline Ovarian $\mathrm{FI}(0-100)$ & $33.15 \pm 8.36(30.47-35.82)^{\ddagger}$ & $34.67 \pm 7.32(32.33-37.01)$ & 0.39 \\
\hline Ovarian VFI (0-100) & $0.91 \pm 0.36(0.79-1.02)^{\ddagger}$ & $0.99 \pm 0.32(0.89-1.09)$ & 0.297 \\
\hline
\end{tabular}

Notes: *Values given as mean \pm standard deviation ( $95 \%$ confidence interval); ${ }^{\ddagger}$ excluding endometrioma.

Abbreviations: $\mathrm{PI}$, pulsatility index; RI, resistance index; VI, vascularization index; FI, flow index; VFI, vascularization $\mathrm{FI}$. 
Table 3 Comparison of endometrial and ovarian Doppler indices according to endometrioma size

\begin{tabular}{|c|c|c|c|}
\hline Variable & Endometrioma $<40 \mathrm{~mm}^{*}$ & Endometrioma $\geq 40 \mathrm{~mm}^{*}$ & $P$-value \\
\hline Patients (n) & 76 & 62 & \\
\hline Endometrial thickness (mm) & $11.06 \pm 3.22(9.63-12.49)$ & $10.12 \pm 3.8(8.56-11.67)$ & 0.402 \\
\hline Uterine artery $\mathrm{PI}$ & $1.44 \pm 0.26(1.33-1.56)$ & $1.56 \pm 0.27(1.43-1.7)$ & 0.162 \\
\hline Uterine artery RI & $0.79 \pm 0.08(0.75-0.82)$ & $0.83 \pm 0.14(0.76-0.9)$ & 0.264 \\
\hline Ovarian artery PI & $1.53 \pm 0.36(1.37-1.69)$ & $1.63 \pm 0.5(1.38-1.88)$ & 0.467 \\
\hline Ovarian artery RI & $0.85 \pm 0.31(0.71-0.99)$ & $0.88 \pm 0.31(0.73-1.03)$ & 0.762 \\
\hline Endometrial volume $\left(\mathrm{cm}^{3}\right)$ & $3.33 \pm I .63(2.6 \mid-4.06)$ & $3.63 \pm 1.14(3.06-4.2)$ & 0.514 \\
\hline Endometrial VI (\%) & $0.5 \pm 0.22(0.4-0.6)$ & $0.4 \pm 0.26(0.27-0.53)$ & 0.195 \\
\hline Endometrial FI $(0-100)$ & $30.12 \pm 9.74(25.8-34.44)$ & $25.7 I \pm 6.92(22.27-29.15)$ & 0.115 \\
\hline Endometrial VFI (0-100) & $0.34 \pm 0.59(0.08-0.6)$ & $0.33 \pm 0.38(0.14-0.52)$ & 0.951 \\
\hline Ovarian volume $\left(\mathrm{cm}^{3}\right)^{\ddagger}$ & $9.21 \pm 3.28(7.75-10.66)$ & $9.34 \pm 3.33(7.68-10.99)$ & 0.902 \\
\hline Ovarian VI (\%) ${ }^{\ddagger}$ & $1.7 \pm 0.89(|.3|-2 . \mid)$ & $1.79 \pm 0.82(1.38-2.2)$ & 0.744 \\
\hline Ovarian FI $(0-100)^{\ddagger}$ & $35.42 \pm 8.64(31.59-39.25)$ & $31.36 \pm 7.31$ (27.72-35) & 0.122 \\
\hline Ovarian VFI $(0-100)^{\ddagger}$ & $0.95 \pm 0.37(0.79-1.12)$ & $0.86 \pm 0.34(0.68-1.03)$ & 0.432 \\
\hline
\end{tabular}

Notes: *Values given as mean \pm standard deviation ( $95 \%$ confidence interval); ${ }^{\ddagger}$ excluding endometrioma.

Abbreviations: PI, pulsatility index; RI, resistance index; VI, vascularization index; FI, flow index; VFI, vascularization FI.

in women undergoing IVF after laparoscopic ovarian cystectomy for large endometriomas $(>6 \mathrm{~cm})$. Porpora et a $1^{15}$ also found a statistically significant improvement in uterine artery flow and pregnancy rate after laparoscopic surgery in patients with ovarian endometrioma.

Whether an ovarian endometrioma should be removed before IVF remains controversial. Surgical excision of endometriomas may be associated with reduced ovarian reserve, ${ }^{16,17}$ due to inadvertent removal of healthy ovarian tissue, thermal injury, or scarring. ${ }^{18,19}$ On the other hand, fenestration and coagulation of endometriomas may be less deleterious to ovarian function; however, the risk of recurrence is higher. ${ }^{20,21}$

Almog et $\mathrm{al}^{22}$ evaluated the effects of ovarian endometrioma on the number of oocytes retrieved for IVF. They reported no significant difference in the number of antral follicles and oocytes retrieved in the endometrioma-containing ovary or in the opposite ovary. There was no correlation between the size and number of endometriomas with the number of retrieved oocytes. Antral follicle count and the number of retrieved oocytes in these women were similar to those in women with no endometrioma.

Some of the limitations to our work included not assessing the stage of endometriosis. While all cases in the study group had endometriomas, the degree of disease was not evaluated, as this mandated that all patients undergo laparoscopy. The same argument can be made for the women with unexplained infertility in the control group, as they may have had mild peritoneal disease that could only be evaluated through laparoscopy.

\section{Conclusion}

The presence of ovarian endometriomas is not associated with impaired endometrial or ovarian blood flows in infertile women scheduled for IVF. Based on our findings, we can hypothesize that ovarian endometriomas are not likely to affect endometrial receptivity or ovarian function through a vascular mechanism, so we can recommend IVF without surgical removal of endometriomas. However, further studies are needed to correlate these findings with the results

Table 4 Comparison of ovarian Doppler indices between endometrioma-containing ovaries and contralateral ovaries

\begin{tabular}{|c|c|c|c|}
\hline Variable & Ipsilateral ovary* & Contralateral ovary* & $P$-value \\
\hline Patients (n) & 138 & 138 & \\
\hline Ovarian artery $\mathrm{PI}$ & $1.7 \pm 0.43(1.56-1.84)$ & $1.56 \pm 0.32(1.45-1.66)$ & 0.103 \\
\hline Ovarian artery RI & $0.9 \pm 0.24(0.82-0.98)$ & $0.89 \pm 0.30(0.79-0.99)$ & 0.870 \\
\hline Ovarian volume $\left(\mathrm{cm}^{3}\right)$ & $9.7 \pm 4.1(8.39-11.01)^{\ddagger}$ & $8.81 \pm 4.49(7.37-10.25)$ & 0.357 \\
\hline Ovarian VI (\%) & $1.75 \pm 0.83(1.49-2.01)^{\ddagger}$ & $1.58 \pm 0.87(1.31-1.86)$ & 0.374 \\
\hline Ovarian FI (0-100) & $33.88 \pm 8.66(31.11-36.65)^{\ddagger}$ & $31.7 I \pm 8.14$ (29.|I-34.3I) & 0.252 \\
\hline Ovarian VFI (0-100) & $0.90 \pm 0.42(0.77-1.03)^{\ddagger}$ & $0.98 \pm 0.37(0.86-I . I)$ & 0.369 \\
\hline
\end{tabular}

Notes: *Values given as mean \pm standard deviation ( $95 \%$ confidence interval); ${ }^{\ddagger}$ excluding endometrioma.

Abbreviations: $\mathrm{PI}$, pulsatility index; $\mathrm{RI}$, resistance index; $\mathrm{VI}$, vascularization index; $\mathrm{FI}$, flow index; $\mathrm{VFI}$, vascularization $\mathrm{FI}$. 
of ovarian stimulation, implantation, and pregnancy rates in IVF.

\section{Disclosure}

The authors report no conflicts of interest in this work. This research did not receive any specific grant from any funding agency in the public, commercial, or not-for-profit sector.

\section{References}

1. Dunselman GA, Vermeulen N, Becker C, et al. ESHRE guideline: management of women with endometriosis. Hum Reprod. 2014;29(3): 400-412.

2. Barnhart K, Dunsmoor-Su R, Coutifaris C. Effect of endometriosis on in vitro fertilization. Fertil Steril. 2002;77(6):1148-1155.

3. Alcázar JL. Transvaginal colour Doppler in patients with ovarian endometriomas and pelvic pain. Hum Reprod. 2001;16(12):2672-2675.

4. Seckin B, Oruc AS, Turkcapar F, Ugur M. The relation of pelvic pain and dense adhesions to Doppler ultrasound findings in patients with ovarian endometriomas. Arch Gynecol Obstet. 2013;287(4):723-728.

5. Wu MH, Cheng YC, Chang FM. Ultrasonographic assessment of ovarian endometrioma. J Med Ultrasound. 2008;16(4):241-248.

6. Moore J, Copley S, Morris J, Lindsell D, Golding S, Kennedy S. A systematic review of the accuracy of ultrasound in the diagnosis of endometriosis. Ultrasound Obstet Gynecol. 2002;20(6):630-634.

7. El-Mazny A, Ramadan W, Kamel A, Gad-Allah S. Effect of hydrosalpinx on uterine and ovarian hemodynamics in women with tubal factor infertility. Eur J Obstet Gynecol Reprod Biol. 2016;199:55-59.

8. Järvelä IY, Sladkevicius P, Tekay AH, Campbell S, Nargund G. Intraobserver and interobserver variability of ovarian volume, gray-scale and color flow indices obtained using transvaginal three-dimensional power Doppler ultrasonography. Ultrasound Obstet Gynecol. 2003; 21(3):277-282.

9. Tan SL. Clinical applications of Doppler and three-dimensional ultrasound in assisted reproductive technology. Ultrasound Obstet Gynecol. 1999;13(3):153-156.

10. Kupesic S. The present and future role of three-dimensional ultrasound in assisted conception. Ultrasound Obstet Gynecol. 2001;18(3): 191-194.
11. Bordes A, Bory AM, Benchaïb M, Rudigoz RC, Salle B. Reproducibility of transvaginal three-dimensional endometrial volume measurements with virtual organ computer-aided analysis (VOCAL) during ovarian stimulation. Ultrasound Obstet Gynecol. 2002;19(1):76-80.

12. Wu MH, Tsai SJ, Pan HA, Hsiao KY, Chang FM. Three-dimensional power Doppler imaging of ovarian stromal blood flow in women with endometriosis undergoing in vitro fertilization. Ultrasound Obstet Gynecol. 2003;21(5):480-485.

13. Alcázar JL, Laparte C, Jurado M, López-García G. The role of transvaginal ultrasonography combined with color velocity imaging and pulsed Doppler in the diagnosis of endometrioma. Fertil Steril. 1997;67(3):487-491.

14. Huang CY, Wang HI, Wang PH, et al. Mean grey value is lower in endometriomas: differentiating a hypoechogenic adnexal cyst by 3-dimensional power Doppler ultrasound - a preliminary study. J Chin Med Assoc. 2011;74(2):75-80.

15. Porpora MG, Tomao F, Manganaro L, et al. Impaired uterine artery flow associated with the presence of ovarian endometrioma: preliminary results of a prospective study. J Ovarian Res. 2014;7:1.

16. Ho HY, Lee RK, Hwu YM, Lin MH, Su JT, Tsai YC. Poor response of ovaries with endometrioma previously treated with cystectomy to controlled ovarian hyperstimulation. J Assist Reprod Genet. 2002;19(11): 507-511.

17. Ragni G, Somigliana E, Benedetti F, et al. Damage to ovarian reserve associated with laparoscopic excision of endometriomas: a quantitative rather than a qualitative injury. Am J Obstet Gynecol. 2005;193(6): 1908-1914.

18. Somigliana E, Arnoldi M, Benaglia L, Iemmello R, Nicolosi AE, Ragni G. IVF-ICSI outcome in women operated on for bilateral endometriomas. Hum Reprod. 2008;23(7):1526-1530.

19. Busacca M, Vignali M. Endometrioma excision and ovarian reserve: a dangerous relation. J Minim Invasive Gynecol. 2009;16(2):142-148.

20. Saleh A, Tulandi T. Reoperation after laparoscopic treatment of ovarian endometriomas by excision and by fenestration. Fertil Steril. 1999; 72(2):322-324.

21. Donnez J, Wyns C, Nisolle M. Does ovarian surgery for endometriomas impair the ovarian response to gonadotropin? Fertil Steril. 2001; 76(4):662-665.

22. Almog B, Shehata F, Sheizaf B, Tan SL, Tulandi T. Effects of ovarian endometrioma on the number of oocytes retrieved for in vitro fertilization. Fertil Steril. 2011;95(2):525-527.
International Journal of Women's Health

\section{Publish your work in this journal}

The International Journal of Women's Health is an international, peerreviewed open-access journal publishing original research, reports, editorials, reviews and commentaries on all aspects of women's healthcare including gynecology, obstetrics, and breast cancer. The manuscript management system is completely online and includes

\section{Dovepress}

a very quick and fair peer-review system, which is all easy to use. Visit http://www.dovepress.com/testimonials.php to read real quotes from published authors. 